Ann. Biol. anim. Bioch. Biophys., I974, 14 (3), 499-5I9.

\title{
LE RÔLE DE LA SÉCRÉTION PANGRÉATIQUE EXOCRINE DANS L'ABSORPTION INTESTINALE DU CHOLESTÉROL GHEZ LE LAPIN
}

\author{
C. DEMIGNE, Christiane VAITON et C. BACQUES \\ Laboratoive de Physiologie, Institut universitaive de Technologie, \\ 43, boulevard du 11-Novembre-1918, \\ 69100 Villeurbanne
}

\section{RÉSUMÉ}

Pour préciser le rôle et les limites de la sécrétion pancréatique exocrine dans le métabolisme intestinal et l'absorption du cholestérol et de ses esters chez le Lapin, il a été procédé à deux groupes d'épreuves :

In vivo, des animaux normaux ou privés de sécrétion pancréatique externe par ligature du Wirsung sont soumis à un régime enrichi en cholestérol.

In vitro, ont été étudiées l'orientation des activités cholestérol-estérasiques sur le suc pancréatique et les contenus digestifs prélevés à différents niveaux du tube intestinal.

Dans ces types d'expériences, l'administration d'émulsion renfermant du cholestérol libre tritié ou de l'oléate de cholestéryle marqué au carbone $\mathbf{I}_{4}$ sur le noyau stérol a permis de suivre leur devenir intraluminal et dans la muqueuse intestinale.

Les résultats sont les suivants :

I $^{0}$ La ligature du canal de Wirsung ne modifie pas la lipémie du Lapin en régime normal. Elle diminue la capacité d'assimilation du cholestérol exogène d'environ six fois, bien que les animaux ingèrent la même quantité d'aliments et dans le même temps que les témoins.

$2^{\circ}$ L'absorption par la muqueuse jéjunoiléale est la plus importante et dépend étroitement de la présence de sécrétion pancréatique. La fraction estérifiée du cholestérol est absorbée vers l'iléon proximal. Ce décalage est probablement dû au retard qu'apporte l'étape de l'hydrolyse.

$3^{\circ}$ L'absorption duodénale ne représente que $15 \mathrm{p}$. Ioo du cholestérol total absorbé par l'ensemble du grêle, soit une quantité trop faible pour intervenir de façon notable sur la lipémie. Elle n'est pas affectée par la suppression de la sécrétion pancréatique et elle concerne le cholestérol libre et les esters de cholestéryle.

$4^{\circ}$ A l'exception de l'intense activité du contenu duodénal, les activités hydrolytiques de tous les niveaux du tube digestif proviennent de la cholestérol estérase du suc pancréatique et vont en s'affaiblissant en direction aborale.

L'activité hydrolytique du contenu gastrique est probablement apportée par l'enzyme pancréatique subsistant dans les cæecotrophes que le Lapin réingère. Dans cette espèce, cette action s'exerce normalement au $\mathrm{pH}$ de l'estomac.

La discussion cherche à donner les caractéristiques de la réponse digestive du Lapin aux régimes enrichis en cholestérol. 


\section{INTRODUCTION}

Nos connaissances sur le métabolisme du cholestérol chez les herbivores sont encore fragmentaires, malgré leur grand intérêt en raison de l'utilisation intensive du Lapin dans les recherches sur l'athérome. Ce rongeur possède en effet la particularité de développer, en présence de régimes enrichis en cholestérol, des perturbations du métabolisme lipidique et des dépôts athéromateux susceptibles de servir de modèle expérimental pour l'étude de ces troubles chez 1'Homme (PopJaK, I949; Favarger et MÉTZGER, I952 ; DALLOChIo et al., I969).

Les conceptions actuelles sur le mécanisme de l'absorption intestinale du cholestérol proviennent en grande partie des données acquises sur le Rat (BYERs, FrIEDMANn et GunNing, I953 ; SWEl, et al., I958 ; Dunham et al., I959; Borgstrom et al., I968) et, dans une moindre mesture, sur le Chien et l'Homme (Borgstrom, ig60 ; Heliman, Frazell et RosenFeld, I960). D'après ces travaux il semble que le cholestérol soit absorbé surtout dans la première moitié du grêle, duodénum distal et jéjunum (BorgSTROM, Ig6o ; FELDMAN et HENDERSON, I969), toutefois ce point est encore parfois controversé (BUCHWALD et GEBHARD, I964). TREADWELL et VAHOUNY (I964) et GoODMAN et SGIRATORI (I969) ont montré qu'il était nécessaire que la fonction hydroxyle soit libre pour enregistrer une absorption du cholestérol, bien que l'on retrouve ce composé estérifié à $75-90$ p. Ioo par des acides gras dans la lymphe (TREADWELL, I958). L'importance de cette estérification reste discutée; Hernandez et al. (I954) et Galio-Torres, Milizer et Hamilton (I97I) lui attribuent un rôle relativement mineur.

Certaines particularités du Lapin ont été soulignées pour tenter d'expliquer son aptitude à développer des hypercholestérolémies.

Le Lapin absorbe environ 80 p. Ioo du cholestérol ingéré (Cook, KLIMAN et FIESER, I954) alors que cette proportion est de 40 à $80 \mathrm{p}$. IOO selon les auteurs chez le Rat, environ $60 \mathrm{p}$. Ioo chez le Chien et de 20 à $50 \mathrm{p}$. Ioo chez l'Homme.

De tous les rongeurs étudiés, BEHER, BAKER et PENNEY (I963) ont montré que le Lapin était celui qui éliminait le plus lentement le cholestérol marqué, la radioactivité plasmatique et hépatique demeurant à un niveau élevé.

Ce fait est en accord avec les travaux de Chevalier et Philimot (I963) chez le Rat, le transport du cholestérol libre se faisant par l'intermédiaire des chylomicrons.

Nous n'ignorons pas, d'autre part, le phénomène de sécrétion du cholestérol plasmatique dans la lumière intestinale, démontré également chez le Rat par Lu'TroN et CHEVALIER (I972) et pouvant laisser croire à un défaut d'absorption. Nous pensons diminuer cette cause d'erreur en employant des régimes fortement enrichis en cholestérol.

Toutefois d'autres facteurs peuvent conditionner la résistance à l'hypercholestérolémie, par exemple, les possibilités d'adapter la biosynthèse d'acide ascorbique à l'oxydation du cholestérol en excès (Novi'TSII, I97I).

Chez tous les mammifères la sécrétion pancréatique joue un rôle important dans l'absorption du cholestérol (Hernandez, Chaikoff et Kiyasu, I955; BorJa, Vahouny et 'TreadWei, I964). Son action s'exerce selon deux modalités; d'une 
part en favorisant la dispersion sous forme de micelles en collaboration avec les acides biliaires; d'autre part, bien que son rôle exact soit controversé (RIBET et PASCAL, I968), grâce à la cholestérol estérase pancréatique. Cette enzyme catalyse réversiblement l'estérification de cholestérol. Dans les conditions de $\mathrm{pH}$ pour l'intestin, 1'hydrolyse semble l'emporter sur l'estérification (KORZENOVSKy et al., I960). Le rôle de cette sécrétion chez le Lapin est fort mal connu (on retiendra les travaux de FAVARGER en 1942 attribuant à la cholestérol estérase un rôle estérifiant) d'autant plus que la disposition anatomique particulière du canal de Wirsung (débouchant en fin de duodénum) ne permet pas de transposer directement les données obtenues sur d'autres mammifères.

Nous traiterons d'un point particulier et mal connu de la principale voie d'entrée du cholestérol dans le pool de l'organisme du Lapin, nous réservant ultérieurement de prendre en considération le sort des autres stérols intestinaux. Nous nous proposons de préciser le rôle de la sécrétion pancréatique sur l'apport de cholestérol exogène en utilisant des régimes surchargés d'une part, d'autre part sur les processus d'estérification du cholestérol libre (ou d'hydrolyse des esters) qui ont lieu dans le tube digestif par des épreuves in vivo et in vitro.

\section{MATÉRIEL ET MÉTHODES}

\section{Techniques préparatives physiologiques}

Maintenance des animaux : des lapins blancs mâles, âgés de 6 mois, de $3 \mathrm{~kg}$ environ, sont placés en batterie à abreuvement automatique et nourris de granulés comportant 5 p. Ioo de matières cellulosiques, $9 \mathrm{p}$. Ioo de matières minérales, I $5 \mathrm{p}$. Ioo de matières protéiques brutes et 3 p. Ioo de matières grasses $\left(C_{16: 0}=17,8\right.$ p. I00; $C_{18: 0}=I 6,5$ p. I00; $C_{18: 1}=4 \mathrm{I}$,I p. I00; $\mathrm{C}_{18: 2}=\mathrm{I} 7,5$ p. 100)

A leur réception les animaux sont placés 15 jours en observation avant toute expérimentation puis sont répartis au hasard dans les différents lots.

Ligature du canal de Wirsung : les lapins à jeun depuis 24 h sont anesthésiés au Nembutal selon les indications de MURdock (I969). L'opération est réalisée dans les conditions d'aseptie chirurgicale; le canal de Wirsung est dégagé puis sectionné entre deux ligatures à un ou deux centimètres au-dessus de l'abouchement à l'intestin.

Recueil du suc pancréatique : les animaux ne sont pas mis à jeun afin de conserver une sécrétion normale. Un cathéter de I $\mathrm{mm}$ de diamètre interne est introduit dans le canal de Wirsung. l'extrémité libre ressort en position dorsale. Le suc est recueilli à $0^{\circ} \mathrm{C}$ et sur taurocholate de sodium de façon à protéger la cholestérol estérase de l'inactivation trypsique, qui, selon VAHouny, WeERsing et TrEadWell (1964 a), est totale en ro minutes à température ordinaire. Ce suc est conservé à $-15^{\circ} \mathrm{C}$ et nous avons pu vérifier que dans ces conditions l'activité cholestérol estérasique demeurait inchangée pendant au moins deux mois.

\section{Étude de l'infuence de la ligature du canal de Wirsung sur l'apport de cholestérol à l'organisme}

Nous avons constitué 4 lots de 4 lapins d'apparence identique, dont la prise de nourriture moyenne est de $\mathrm{I} 40 \mathrm{~g} / \mathrm{j}$. Les lots A (lapins non opérés) et B (lapins sans sécrétion pancréatique) reçoivent un régime normal. Les lots C (lapins non opérés) et D (lapins sans sécrétion pancréatique) reçoivent le régime enrichi en cholestérol.

On réalise le régime surchargé en cholestérol par l'apport quotidien de I $g$ de cholestérol fixé sur $70 \mathrm{~g}$ de granulés après dissolution dans l'éther éthylique et évaporation. La ration journalière est complétée à r $40 \mathrm{~g}$.

Les animaux ont toujours consommé la même quantité de granulés que les témoins.

Les prélèvements sanguins par ponction cardiaque sont effectués toutes les semaines à to heures. On a remarqué que la prise de nourriture demeure constante tout au long du nycthémère. 


\section{Étude in vivo $d u$ sort du cholestérol libre ou estérifié dans l'intestin}

\section{Préparation des émulsions.}

Émulsion A : $5 \mu \mathrm{Ci}$ de cholestérol libre tritié $\left({ }^{3} \mathrm{H}_{\mathrm{G}}\right)$ ou sa forme estérifiée par l'acide oléique sont dissouts dans $0,2 \mathrm{ml}$ d'acétone et émulsionnés à $3^{80} \mathrm{C}$ par $0,5 \mathrm{ml}$ d'une solution de taurocholate de $\mathrm{Na}$ à $20 \mathrm{mg} / \mathrm{ml}$.

Émulsions B : $80 \mathrm{mg}$ de cholestérol ou $138 \mathrm{mg}$ d'oléate de cholestéryle sont dissouts dans $2 \mathrm{ml}$ d'éther éthylique puis mis en suspension dans $9,5 \mathrm{ml}$ d'une solution de taurocholate de $\mathrm{Na}$ à $5 \mathrm{mg} / \mathrm{ml}$ par agitation à l'aide de l'ultraturax (20 0oo $\mathrm{tr} / \mathrm{mn})$ pendant 20 secondes.

L'émulsion B est ajou tée à l'émulsion A correspondante et le mélange est placé au bain-marie à $3^{8} \mathrm{C}$ jusqu'à disparition de l'odeur d'éther. L'émulsion lactescente est stable au moins un mois $\grave{a}+2^{\circ} \mathrm{C}$ (radioactivité spécifique $=137500 \mathrm{~d} . \mathrm{p} . \mathrm{m} . / \mathrm{mg}$ de cholestérol) .

L'émulsion doublement marquée est préparée de façon similaire mais contient $2,5 \mu \mathrm{Ci}$ de cholestérol- $-{ }^{14} \mathrm{C}$ et $2,5 \mu \mathrm{Ci}$ d'oléate de cholestéryle $\left({ }^{3} \mathrm{H}_{\mathrm{G}}\right)$ et mélangé à $40 \mathrm{mg}$ de cholestérol et $69 \mathrm{mg}$ d'oléate de cholestéryle.

On forme 2 groupes de 9 lapins, le premier constitué d'animaux normaux et le second de lapins privés de sécrétion pancréatique.

\section{Étude des contenus digestifs.}

Chaque lapin reçoit ro $\mathrm{ml}$ d'émulsion par sondage naso-œsophagien. Le contenu de la sonde est chassé par insuflation de $2 \mathrm{ml}$ d'air. Les prélèvements sont effectués à 45 , 90 minu tes et 3 heures après administration de l'émulsion : 3 animaux sont sacrifiés par temps de prélèvement en leur injectant io $\mathrm{ml}$ d'air dans le cœur. A près ouverture de l'abdomen, on délimite entre deux ligatures les portions du tube digestif à prélever (estomac, duodénum, jéjunum, iléon, cœecum et côlon). Leurs contenus respectifs sont rapidement brassés et l'on prélève $2 \mathrm{~g}$ de matière par compartiment pour doser le cholestérol libre ct estérifié et en déterminer les radioactivités spécifiques.

\section{Etudes dans la muqueuse intestinale.}

Lors des prélèvements, les segments intestinaux sont abondamment rincés au sérum physiologique glacé, puis éversés et soumis à un nouveau rinçage. La muqueuse est alors récupérée par raclage.

Fitude in vitro de l'influence de la sécrétion pancréatique. sur les activités cholestérol estérasiques de contenus digestifs

\section{Activité intrinsèque du suc pancréatique.}

Les estérifications sont étudiées sur des milieux tamponnés $(\mathrm{pH} 6,2)$ d'après les conditions proposées par ShaH, Lossow et CHaikoff ( 1965 ). En raison de la faible solubilité dans l'acétone des esters de cholestéryle saturés nous avons modifié le milieu en dissolvant les substrats dans l'éther éthylique (à $\mathrm{pH} 7,2$ ).

L'équilibre de la réaction d'estérification de l'acide oléique est atteint au bout de 3 heures, alors qu'il faut 6 heures pour les substrats saturés. Afin d'obtenir des informations transposables in vivo, nous nous sommes limités à des incubations de 3 heures.

\section{Activités des contenus digestifs.}

La technique d'incubation est une variante de celle proposée par Rosenfeld et Hellman (197I). Chaque incubation sur $2 \mathrm{ml}$ d'homogénat de contenu digestif dilué au $\mathrm{I} / 4$ dans le sérum physiologique est effectuée en présence O,I $\mu$ Ci de cholestérol $\left({ }^{3} \mathrm{H}_{\mathrm{G}}\right)$ ou d'oléate de cholestéryle tritié.

Les contenus de tous les niveaux du tube digestif proviennent : de lapins non opérés témoins ( $\operatorname{lot}, \mathrm{A}, \mathrm{N}=3$ ); de lapins privés de sécrétion pancréatique (lot $\mathrm{B}, \mathrm{N}=3$ ) et pour l'expérience $\mathrm{C}$ de contenus provenant des lapins du lot $B$ dans les homogénats desquels on a ajouté $50 \mu l$ de suc pancréatique $(0,2 \mathrm{mg}$ de protéines).

La cinétique de la réaction est suivic pendant 2 heures $\grave{a} 37^{\circ} \mathrm{C}$ sous agitation constante. 


\section{Techniques d'analyse}

Les lipides totaux sont extraits selon la technique de Delsal (1944) au méthylal-méthanol; la technique de Beukers, VeltKamp et Hoogwinkel (1969) par le mélange alcool-acétone, n'est utilisée que pour les extractions de cholestérol des milieux d'incubation in vitro. Les différentes classes lipidiques sont séparées sur couche mince de silicagel $\mathrm{G}$ de $0,25 \mathrm{~mm}$ d'épaisseur. Le solvant de migration est un mélange d'éther de pétrole-éther éthylique-acide acétique ( $70: 30: 2, \mathrm{v} / \mathrm{v} / \mathrm{v}$ ). Les fractions séparées sont révélées soit par l'iode (détermination de cholestérolémies ou de radioactivités) soit par une solution alcoolique de Rhodamine B à $0,05 \mathrm{p}$. Ioo en vue d'une analyse ultérieure des acides gras par chromatographique en phase gazeuse.

Le cholestérol est dosé directement à partir des éluats des taches récupérées sur les plaques par la technique colorimétrique de $Z_{\text {LATKIS, }} Z_{\mathrm{AK}}$ et BOYLE (I953). Les autres classes lipidiques sont déterminées par dosage de leurs acides gras par CPG (KuKsis, I966) en présence d'une quantité exactement connue d'étalon interne (acide heptadécanoïque). Les esters méthyliques sont préparés par transméthylation au trifluorure de bore-méthanol selon les indications de MoRRISON et Sмr'rH (1964). Les esters sont ensuite séparés par chromatographie en phase gazeuse sur colonnes

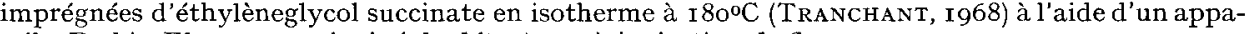
reil "Perkin-Elmer 900 " équipé de détecteurs à ionisation de flamms.

Les comptages de radioactivité sont effectués directement à partir du silicagel (Houx, 1969) par scintillation liquide en utilisant le mélange 2,5-diphényloxazol (PPO) o,3 p. Ioo et 2,2' p-phénylènebis (5-phényloxazol) (POPOP) O,I p. IOo dans le toluène. On utilise un spectromètre Packard type 23II pour les comptages de substances à un seul marquage et on détermine le rendement par la technique des rapports de canaux. En double marquage, les radioactivités sont mesurées sur spectromètre Packard, modèle 3380 et les rendements déterminés à l'aide de standards externes.

La synthèse des esters de cholestéryle (oléate en particulier) est réalisée par voie enzymatique (SWELl et TREADWELL, r962) en utilisant la cholestérol estérase du suc pancréatique de lapin et les conditions proposées par Sнaн, Lossow et Chaikoff (I965), l'ester est ensuite purifié par chromatographie sur couche mince et conservé dans le toluène à $-20^{\circ} \mathrm{C}$.

\section{RÉSULTATS}

\section{A. - Effets de la ligature du canal de Wirsung sur les paramètres du métabolisme lipidique du plasma. Effet d'une surcharge en cholestérol}

La représentation graphique de l'évolution dans le temps des lipémies (fig. I) ne montre aucune différence significative entre les témoins et les animaux opérés recevant le régime normal. Avec le régime enrichi en cholestérol, le taux de lipides totaux croît de façon pratiquement linéaire jusqu'à la quatrième semaine, passant de 3,59 à 22,o g/l. Dès la seconde semaine le plasma prend un aspect lactescent.

Chez les lapins privés de sécrétion pancréatique la lipémie s'élève de 3,47 à $8, \mathbf{r} 3 \mathrm{~g} / 1$ à la quatrième semaine, alors qu'elle reste normale avec le régime non surchargé.

Les cholestérolémies des 2 lots ( $\mathrm{A}$ et $\mathrm{B}$ ) soumis au régime normal se maintiennent autour de $60 \mathrm{mg} / \mathrm{I} 00 \mathrm{ml}$; le rapport cholestérol libre/cholestérol estérifié $\left(\mathrm{C}_{\mathrm{L}} / \mathrm{C}_{\mathrm{E}}\right)$ normalement de 1 'ordre de 0,50 s'élève transitoirement à $I, I_{5}$ à la troisième semaine chez les lapins opérés avant de revenir à la normale à la sixième semaine.

Le régime surchargé s'accompagne d'une forte élévation de la cholestérolémie des lapins non opérés (de 6r,6 à $637,5 \mathrm{mg} / \mathrm{I} 00 \mathrm{ml}$ avec stabilisation vers $55^{\circ} \mathrm{mg} /$ Ioo $\mathrm{ml}$ ). Chez les sujets privés de sécrétion pancréatique, toutefois, la variation s'étage

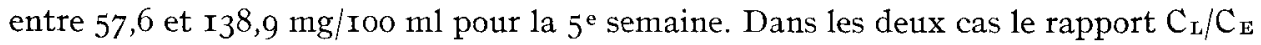
diminue d'emblée de 0,53 à $0,35-0,30$, ce qui signifie que 1'hypercholestérolémie est due principalement à l'élévation du taux des esters de cholestéryle (EC) ; d'ailleurs, 
la cholestérolémie libre des sujets opérés (lot D) ne diffère significativament de celle des témoins que pour la quatrième samaine.

La composition des lipides plasmatiques à la $6^{\text {e }}$ semaine de l'expérience ne montre que peu de variations dans les taux de phospholipides (1a baisse à 20,4 p. Ioo du lot C n'est pas significative) ; de même pour les acides gras non estérifiés dont le taux diminue par rapport aux témoins, mais de façon non significative. Les principales

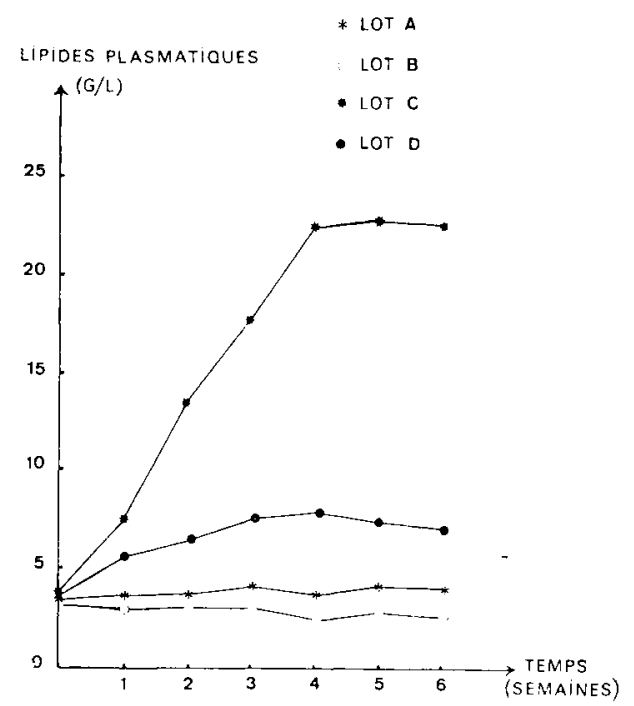

FIG. I. - Évolution en fonction du temps (en semaines) des lipémies plasmatiques exprimées en g/l chez les lapins non opérés (lots $\mathrm{A}$ et $\mathrm{C}$ ) ou privés de sécrétion pancréatique (lots $\mathrm{B}$ et $\mathrm{D}$ ).

Les animaux des lots $A$ et $B$ reçoivent un régime normal et ceux des lots $C$ et 1 reçoivent un régime enrichi en cholestérol à raison de $\mathrm{I} g / \mathrm{j}$.

variations sont localisées aux triglycérides et aux esters de cholestéryle. Dans le lot $\mathrm{C}$ (non opérés) le pourcentage de triglycérides diminue fortement (de 4 fois) par rapport aux témoins, mais comme les lipémies ont été multipliées par 6 la triglycéridémie se trouve néanmoins augmentée de 50 p. Ioo. Dans le lot D (opérés) le taux de triglycétides ne varie pas significativement.

Le pourcentage des esters de cholestéryle diminue dans le lot $\mathrm{B}$ et augmente dans les lots C, et D. La somme des pourcentages des triglycérides et des esters de cholestéryle varie remarquablement peu parmi les quatre lots : A $(62, \mathrm{I}) \mathrm{B}(68,4), \mathrm{C}(67,2)$ et $\mathrm{D}(65, \mathrm{I})$. Il semble que, quelles que soient les conditions expérimentales, la cholestérolémie et la triglycéridémie soient interdépendantes.

\section{B. - Etude in vivo de l'influence de la sécrétion pancréatique sur le sort du cholestérol libre ou estérifié dans l'intestin}

\section{Contenus digestifs.}

Lors de l'administration de cholestérol libre le transit intestinal de la dose marqueuse de cholestérol est mis en évidence par la disparition presque complète de la radioactivité des contenus digestifs au bout de 3 heures. La radioactivité duodénale 


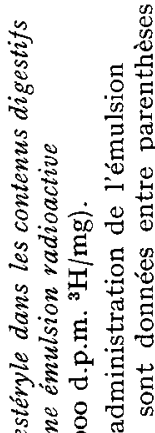

䆠

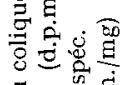

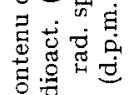

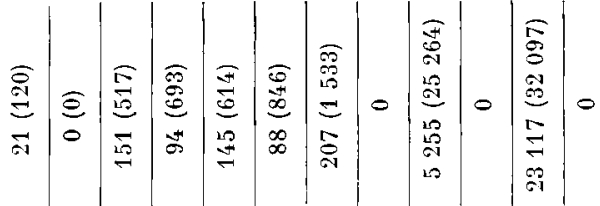

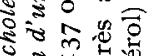

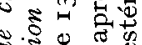

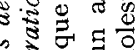

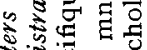
3. है. ڤ 运步

के

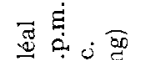

च 造芯芯 要

तु 跑总造

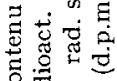

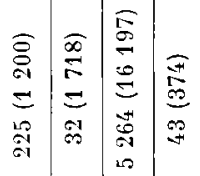

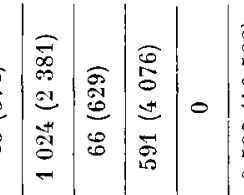

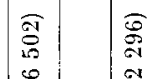
จ 0

खึํำ 要造造

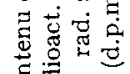
ठ

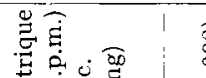
要递兽

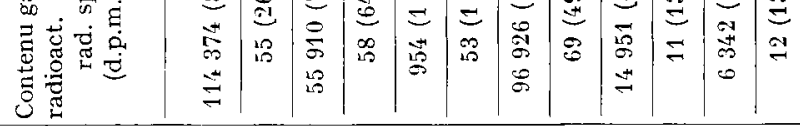
翌

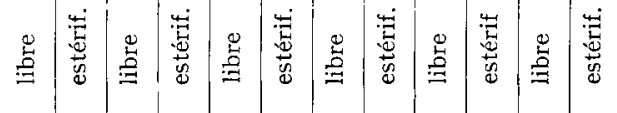

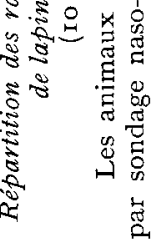

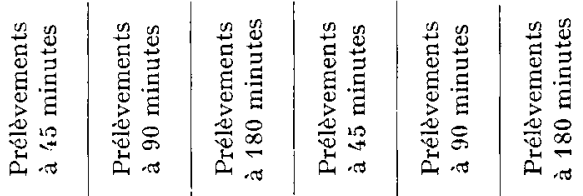

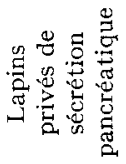


tant en valeur absolue que spécifique, diminue de 20 à $50 \mathrm{p}$. Ioo entre 90 et I $80 \mathrm{mn}$ : on ne la retrouve pas dans les autres segments du grêle. Nous pensons qu'il existe un transit bref dans le duodénum; d'autre part, du cholestérol d'origine biliaire peut refluer vers le duodénum lors du sacrifice de l'animal.

Une radioactivité notable des esters de stérols n'a été retrouvée que chez les lapins non opérés. Les radioactivités de ces esters sont faibles devant celles de la fraction stérols libres ; mais, comme leurs concentrations intraluminales sont basses, les radioactivités spécifiques sont relativement importantes (tabl. I).

Chez les animaux privés de sécrétion pancréatique la radioactivité demeure élevée dans les contenus digestifs, même au bout de $3 \mathrm{~h}$. La différence avec les sujets normaux ne devient sensible qu'au bout de $90 \mathrm{mn}$, délai nécessaire pour observer une vidange gastrique importante du contenu radioactif. L'estérification du cholestérol libre administré est tout à fait nézligeable.

Lors de l'administration d'oléate de cholestéryle la radioactivité se maintient à un niveau élevé au bout de $3 \mathrm{~h}$, ce phénomène étant plus marqué chez les lapins privés de sécrétion pancréatique ; il faut noter que la dilution par le cholestérol estérifié endogène demeure très limitée ce qui explique les fortes radioactivités spécifiques présentes dans les esters.

La radioactivité qui apparait en quantités importantes dans la fraction stérols libres témoigne de l'hydrolyse de l'ester administré. Cette hydrolyse semble débuter dans l'estomac puisque la fraction cholestérol libre présente à $45 \mathrm{mn}$ une radioactivité mesurable (tabl. 2).

La radioactivité trouvée dans la fraction stérols libres est beaucoup plus importante chez les lapins sans sécrétion pancréatique ; comme la radioactivité des esters se maintient aussi à un niveau plus élevé que chez les lapins non opérés, cette augmentation de radioactivité de la fraction libre ne peut être attribuée qu'au défaut d'absorption du cholestérol tritié.

\section{Muqueuse de l'intestin grêle.}

La muqueuse duodénale des lapins normaux retient dès la $45^{\circ} \mathrm{mn}$ une part importante de cholestérol sous forme estérifiée. La radioactivité apparaît plus rapidement dans la muqueuse de l'iléon que dans celle du jéjunum; néanmoins, au bout de $3 \mathrm{~h}$, c'est dans cette dernière que l'on retrouve la plus forte quantité de carbone $\mathrm{I} 4$ (provenant du cholestérol libre).

Au bout de $45 \mathrm{mn}$ l'apparition du tritium dans la muqueuse duodénale est localisée surtout aux esters. Bien que le maximum de tritium soit retrouvé dans la fraction libre retenue par la muqueuse jéjunale, la radioactivité apparaît plus précocement dans la muqueuse iléale.

Chez les lapins sans sécrétion pancréatique, la pénétration du carbone I4 dans les muqueuses jéjunale et iléale est fortement réduite (au I/4 environ). Au contraire 1a muqueuse duodénale se comporte comme celle des lapins témoins. On trouve tout au long du grêle une quantité importante du cholestérol tritié (provenant de l'oléate) dans la fraction esters, surtout au temps de prélèvement $45 \mathrm{mn}$. Cependant, cette incorporation est très diminuée dans la partie distale du grêle où elle reste inférieure à celle du cholestérol libre (fig. 4) . 


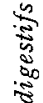

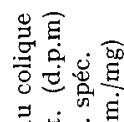

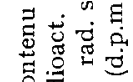

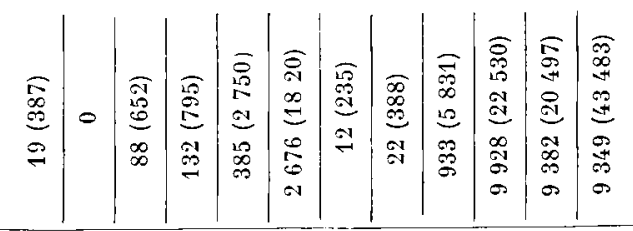

$\int_{\infty}^{\infty}$

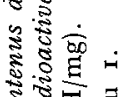

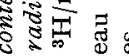

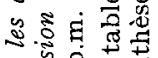

ॐ

है ₹

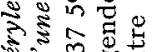

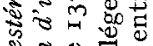

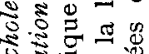

施

\&.

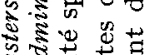

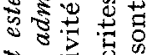

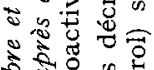

管

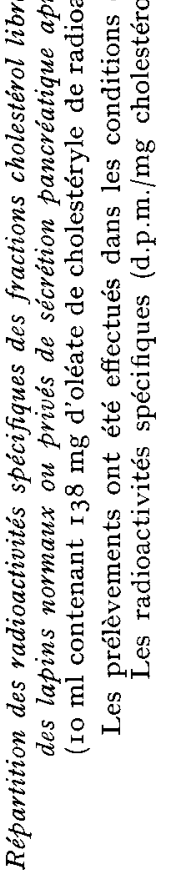

0

$\frac{0}{8}$

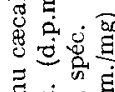

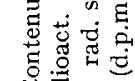

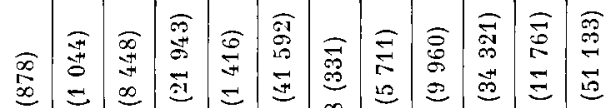

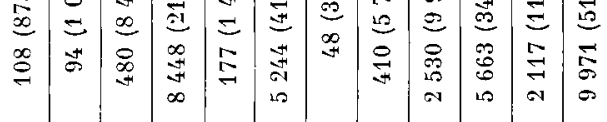

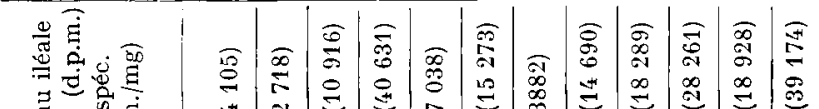

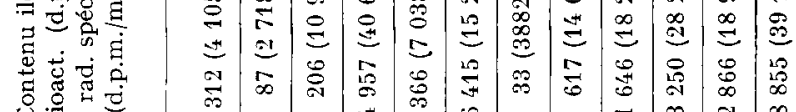

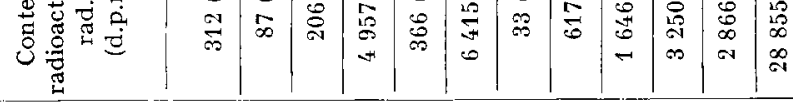

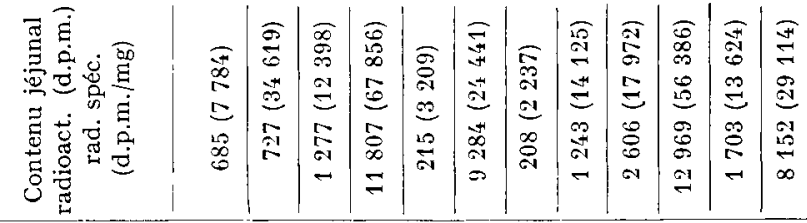

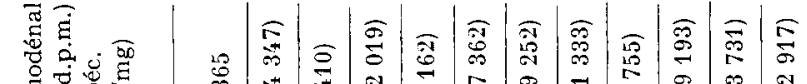

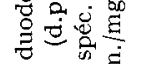

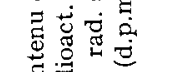

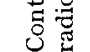

龸

实

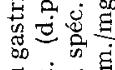

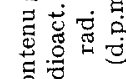

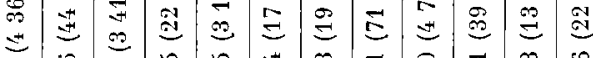

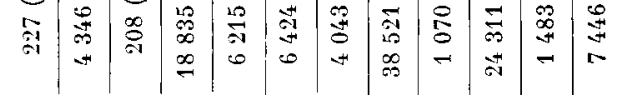

ठํ

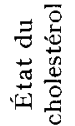

总葶

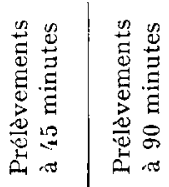

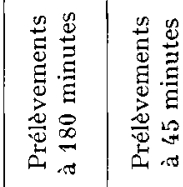

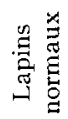

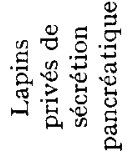




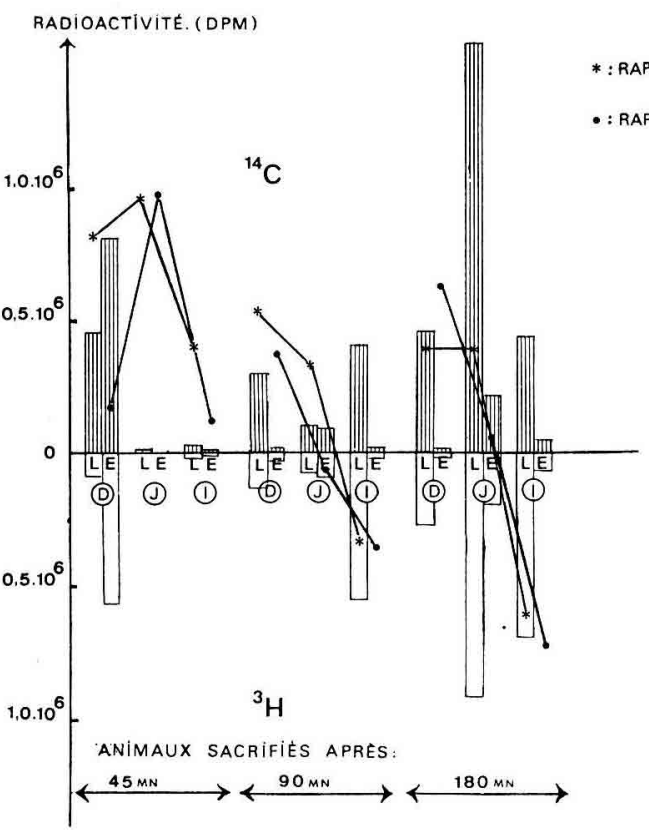

LAPINS NON OPERES

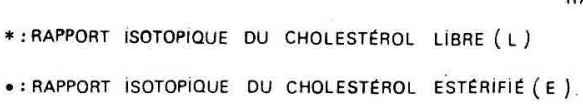

RAPPORT ${ }^{3} \mathrm{H} /{ }^{14} \mathrm{C}$

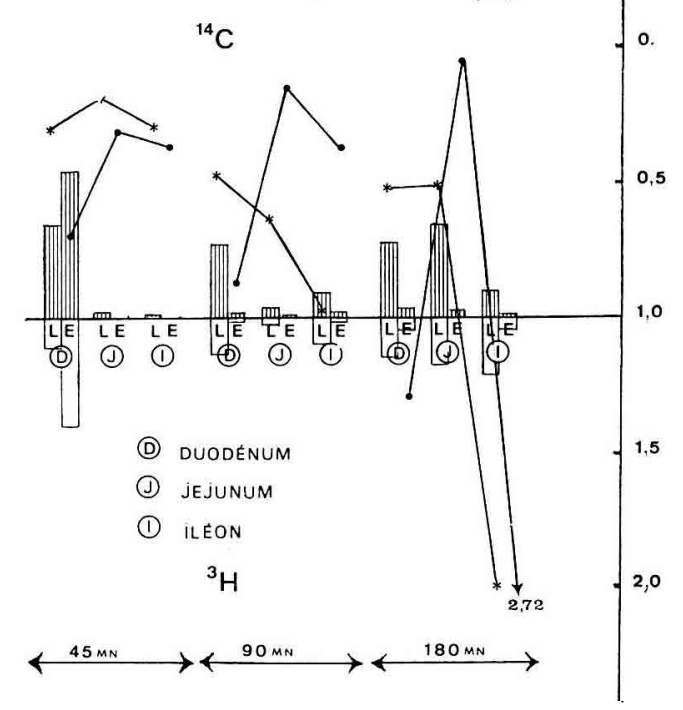

LAPINS PRIVES dE SECRETION PANCREATIQUE

FIG. 4. - Captation in vivo par les muqueuses duodénales (D), jéjunales (J) et iléales (I) du cholestérol libre $\left(4^{-14} \mathrm{C}\right.$ ) ou estérifié (oléate de cholestéryle ${ }^{3} \mathrm{H}_{\mathrm{G}}$ ) après administration de $10 \mathrm{ml}$ d'une émulsion contenant $40 \mathrm{mg}$ de cholestérol libre (radioactivité spécifique : 137500 d.p.m./mg de cholestérol) et $69 \mathrm{mg}$ d'oléate de cholestéryle (radioactivité spécifique : 137000 d.p.m./mg de cholestérol).

Les radioactivités (d.p.m.) des fractions cholestérol libre (L) et esters de cholestéryle (E), ainsi que le rapport isotopique $\left({ }^{3} \mathrm{H} /{ }^{14} \mathrm{C}\right)$ des deux fractions cholestérolées sont donnés pour les temps de prélèvement 45, 90 et I80 minutes après administration de l'émulsion par sondage naso-œsophagien. Ces prélevements ont été effectués d'une part sur un lot de lapins non opérés, d'autre part sur un lot de lapins privés de sécrétion pancréatique.

\section{Degré d'estérification dans la muqueuse.}

Dans la muqueuse duodénale existe une estérification importante du cholestérol libre $\left({ }^{14} \mathrm{C}\right)$ pour les temps courts $(45 \mathrm{mn})$. Les esters formés sont particulièrement riches en trititum provenant de l'oléate de cholestéryle (tritium: $\mathrm{C}_{\mathrm{L}} / \mathrm{C}_{\mathrm{E}}=0, \mathrm{I} 3$; carbone $I_{4}: C_{L} / C_{E}=0,50$ ). Dans la muqueuse jéjunale, l'estérification est perceptible après 90 minutes. Elle fait suite au phénomène d'hydrolyse des esters introduits, si bien que le cholestérol provenant de l'ester oléique devient proportionnellement plus abondant dans les esters néoformés que le cholestérol-4 ${ }^{14} \mathrm{C}$. Chez les lapins opérés on note une faible estérification. On ne retrouve plus de tritium dans les esters.

La muqueuse iléale présente une affinité importante pour le cholestérol libre; le pourcentage d'esters y est assez faible, sauf, comme pour les autres parties du grêle, au moment de l'arrivée du cholestérol. La radioactivité des esters montre chez les lapins normaux une prédominance marquée du tritium (rapport isotopique ${ }^{3} \mathrm{H} /{ }^{14} \mathrm{C}=$ I,70) qui s'explique par l'abondance du tritium dans la fraction libre.

La quantité de cholestérol estérifié reste faible chez les lapins opérés, le rapport isotopique $\left({ }^{3} \mathrm{H} /{ }^{11} \mathrm{C}\right)$ n'est en faveur du tritium que pour les temps $\mathrm{I} 8 \mathrm{O}$ minutes où il est égal à 2,94 pour le $\mathrm{C}_{\mathrm{L}}$ et 2,7I pour les $\mathrm{E}_{\mathrm{C}}$. 


\section{C. -... Étude in vitro de l'infuence de la sécrétion pancréatique sur les activités cholestérol estérasiques des contenus digestifs}

Activité intrinsèque du suc pancréatique.

- Estérification : la cholestérol estérase du suc pancréatique du lapin synthétise avec des rendements élevés des esters de cholestéryle d'acides gras insaturés (oléate et linoléate). Les acides gras saturés sont moins bien estérifiés, l'acide stéarique l'étant cependant 2 fois plus que l'acide palmitique (tab1. 3).

\section{TABLEAU 3}

Activité cholestérol estérasique (estérifiante) du suc pancréatique du lapin

$(0,2 \mathrm{ml}$ soit $0,8 \mathrm{mg}$ de protéines) en présence de différents acides gras

Incubation : $5 \mu$ moles de cholestérol $(\mathrm{O}, \mathrm{I} \mu \mathrm{Ci})$ et $5 \mu$ moles d'acides gras sont dissoutes dans $0,4 \mathrm{ml}$ d'acétone puis émulsionnées par 3,6 $\mathrm{ml}$ de tampon phosphate de $\mathrm{K}$ o, $\mathrm{I} \mathrm{M}(\mathrm{pH}: 6,2)$ contenant Io $\mathrm{mg}$ de taurocholate de sodium. Incubation à $37^{\circ} \mathrm{C}, 2$ heures à agitation constante.

\begin{tabular}{|c|c|c|c|c|c|c|c|}
\hline & & $\begin{array}{c}t_{0} \\
\text { radioactivité } \\
\text { (d.p.m.) }\end{array}$ & $\begin{array}{c}3 \mathrm{~h} \\
\text { (d.p.m.) }\end{array}$ & $\begin{array}{c}3 \mathrm{~h} \\
\text { corrigé } \\
\text { (d.p.m.) }\end{array}$ & $\begin{array}{l}\text { d.p.m. } \\
t_{\mathrm{o}} / 3 \mathrm{~h}\end{array}$ & $\begin{array}{l}\mu \text { moles } \\
\text { estérifiées }\end{array}$ & $\begin{array}{c}\text { estéri- } \\
\text { fication } \\
(\%)\end{array}$ \\
\hline $\begin{array}{l}\text { dipalmitoyl (') } \\
\text { lécithine }\end{array}$ & $\begin{array}{l}\mathrm{L} \\
\mathrm{E}\end{array}$ & $\begin{array}{r}96999 \\
207\end{array}$ & $\begin{array}{r}92 \quad 249 \\
280\end{array}$ & $\begin{array}{r}92249 \\
73\end{array}$ & $\begin{array}{l}97206 \\
92529\end{array}$ & 0,003 & 0,07 \\
\hline $\begin{array}{c}\text { acide } \\
\text { palmitique }\end{array}$ & $\begin{array}{l}\mathrm{L} \\
\mathrm{E}\end{array}$ & $\begin{array}{r}94481 \\
270\end{array}$ & $\begin{array}{r}90635 \\
6370\end{array}$ & $\begin{array}{r}90635 \\
6100\end{array}$ & $\begin{array}{l}94751 \\
97005\end{array}$ & 0,314 & 6,28 \\
\hline $\begin{array}{c}\text { acide } \\
\text { stéatique }\end{array}$ & $\begin{array}{l}\mathrm{L} \\
\mathrm{E}\end{array}$ & $\begin{array}{r}104144 \\
268\end{array}$ & $\begin{array}{l}86793 \\
12235\end{array}$ & $\begin{array}{l}86793 \\
11967\end{array}$ & $\begin{array}{r}104412 \\
92750\end{array}$ & 0,606 & 12,11 \\
\hline $\begin{array}{l}\text { acide } \\
\text { oléique }\end{array}$ & $\begin{array}{l}\mathrm{L} \\
\mathrm{E}\end{array}$ & $\begin{array}{r}94685 \\
315\end{array}$ & $\begin{array}{l}21300 \\
70782\end{array}$ & $\begin{array}{l}21300 \\
70067\end{array}$ & $\begin{array}{l}95001 \\
91367\end{array}$ & 3,834 & 76,68 \\
\hline $\begin{array}{c}\text { acide } \\
\text { linoléique }\end{array}$ & $\begin{array}{l}\mathrm{L} \\
\mathrm{E}\end{array}$ & $\begin{array}{r}95771 \\
293\end{array}$ & $\begin{array}{l}25977 \\
64536\end{array}$ & $\begin{array}{l}25977 \\
64234\end{array}$ & $\begin{array}{l}96064 \\
90220\end{array}$ & 3,560 & 71,20 \\
\hline
\end{tabular}

(') Dissolution dans le méthanol au lieu de l'acétone.

- Hydrolyse : Les activités restent très fortes avec l'oléate, le linoléate, et le butyrate de cholestéryle, alors que les esters saturés sont beaucoup moins fortement clivés ; on retrouve la même distinction que lors de l'épreuve d'estérification : 1'hydro1yse du stéarate est environ deux fois plus forte que celle du palmitate de cholestéryle (tabl. 4).

Activités cholestérol estérasique des contenus digestifs.

- Estérification : pratiquement nulle à tous les niveaux du tube digestif et quel que soit le traitement subi par les lapins, aussi ne présenterons-nous pas de figure. La seule activité notable $(4,5$ à 6,5 p. IOO) a été observée dans le duodénum de 
lapins opérés, l’apport de suc pancréatique ne modifiant pratiquement pas ce degré d'estérification.

- Hydrolyse : chez les lapins non opérés (fig. 5) :

- Dans le contenu gastrique, après un maximum d'hydrolyse rapidement atteint vers $4 \mathrm{I}$ p. Ioo, il semble que le cholestérol libéré soit réestérifié puisque au bout de $2 \mathrm{~h}$, le pourcentage d'hydrolyse n'est plus que de I3 p. Ioo.

- Le contenu duodénal présente une activité intense caractérisée par une hydrolyse rapide et presque totale de l'oléate de cholestéryle.

- Les activités jéjunale et iléale, relativement fortes, sont très voisines (42 et 46 p. Ioo au bout de $2 \mathrm{~h}$ ).

- L'activité du contenu caecal est un peu plus faible, mais la cinétique présente la même allure que celle observée dans le grêle distal. Dans le côlon subsiste une très
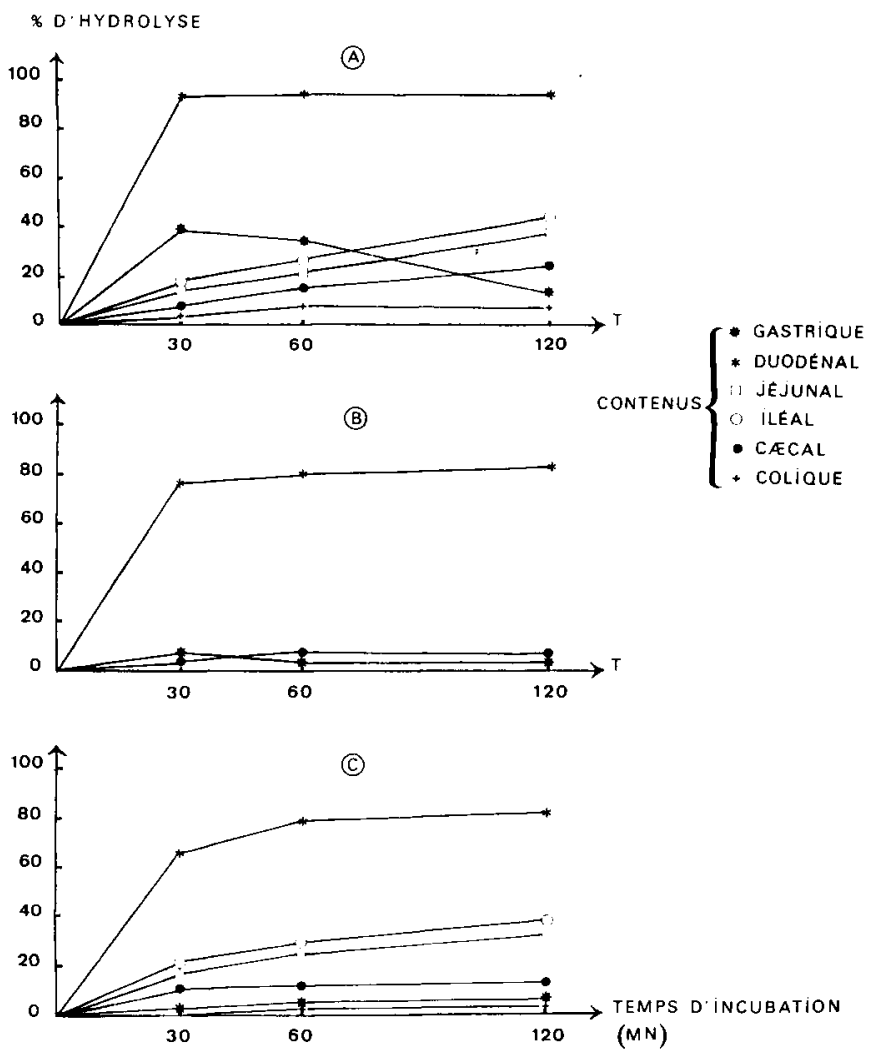

FIG. 5. - Cinétiques de l'hydrolyse de l'oléate de cholestéryle tritié $\left({ }^{3} \mathrm{H}_{\mathrm{G}}\right)$ en présence d'homogénats de contenus digestifs de lapins (A) non opérés; (B) privés de sécrétion pancréatique ; (C) privés de sécrétion pancréatique, dans les homogénats desquels 50 pl de suc pancréatique (o,2 $\mathrm{mg}$ de protéines) ont été rajoutés.

Dans l'expérience $B$, les hydrolyses obtenues à partir d'homogénats de contenus de jéjunum, d'iléon et de côlon n'ont pas été représentées étant donné qu'elles sont négligeables.

Le substrat (oléate de cholestéryle ${ }^{3} \mathrm{H}_{\mathrm{G}}: 0, \mathrm{I} \mu \mathrm{Ci}$ ) est dissout dans $\mathrm{o}, \mathrm{I} \mathrm{ml}$ d'une solution de Tween 80 à 0,5 o. Ioo dans l'éthanol $95^{\circ}$ qui est ensuite évaporé. L'ester est alors repris par $2,5 \mathrm{ml}$ de $\mathrm{NaCl}$ $9 \mathrm{p}$. I ooo et incubé à $37^{\circ} \mathrm{C}$ en présence de $2 \mathrm{ml}$ d'homogénat de contenu digestif dilué au $\mathrm{I} / 4 \mathrm{par} \mathrm{du}$ sérum physiologique. 


\section{TABIEAU 4}

Activité cholestérol estérasique (hydrolytique) du suc pancréatique du lapin $(0,2 \mathrm{ml}$ soit $0,8 \mathrm{mg}$ de protéines) en présence de différents esters de cholestéryle

Incubation : $5 \mu$ moles d'ester de cholestéryle sont dissoutes dans $0,4 \mathrm{ml}$ d'éther éthylique puis mis en émulsion par $\mathrm{O}, \mathrm{I} \mathrm{ml}$ d'une solution tamponnée contenant $\mathrm{I}$ o $\mathrm{mg}$ de taurocholate de sodium. Le mélange est complété à $4 \mathrm{ml}$ avec du tampon phosphate de $\mathrm{K} 0, \mathrm{I} \mathrm{M}(\mathrm{pH} 7,2)$. Incubation à $37^{\circ} \mathrm{C}, 2 \mathrm{~h}$ à agitation constante.

\begin{tabular}{|c|c|c|c|c|c|c|c|}
\hline & & $\begin{array}{c}t_{0} \\
\text { poids cholest. }\end{array}$ & $\begin{array}{l}3 \mathrm{~h} \\
(\gamma)\end{array}$ & $\begin{array}{c}3 \mathrm{~h} \\
\text { corrigé } \\
(y)\end{array}$ & $\begin{array}{c}\text { cholest. } \\
\text { total } \\
t_{\mathrm{o}} / 3 \mathrm{~h}(\gamma)\end{array}$ & $\begin{array}{c}\mu \text { moles } \\
\text { hydrolysées }\end{array}$ & $\begin{array}{c}\text { hydrolyse } \\
(\%)\end{array}$ \\
\hline $\begin{array}{c}\text { butyrate } \\
\text { de cholestérol }\end{array}$ & $\begin{array}{l}\mathrm{L} \\
\mathrm{E}\end{array}$ & $\begin{array}{r}21 \\
1724\end{array}$ & $\begin{array}{r}1789 \\
72\end{array}$ & $\begin{array}{r}1767 \\
72\end{array}$ & $\begin{array}{l}1745 \\
1839\end{array}$ & 4,804 & 96,08 \\
\hline $\begin{array}{c}\text { palmitate } \\
\text { de cholestérol }\end{array}$ & $\begin{array}{l}\mathrm{L} \\
\mathrm{E}\end{array}$ & $\begin{array}{r}23 \\
1802\end{array}$ & $\begin{array}{r}342 \\
1509\end{array}$ & $\begin{array}{r}319 \\
1509\end{array}$ & $\begin{array}{l}1825 \\
1828\end{array}$ & 0,872 & 17,45 \\
\hline $\begin{array}{c}\text { stéarate } \\
\text { de cholestérol }\end{array}$ & $\begin{array}{l}\mathrm{L} \\
\mathrm{E}\end{array}$ & $\begin{array}{r}23 \\
1754\end{array}$ & $\begin{array}{r}660 \\
1076\end{array}$ & $\begin{array}{r}660 \\
1076\end{array}$ & $\begin{array}{l}1777 \\
1736\end{array}$ & 1,900 & 38,01 \\
\hline $\begin{array}{c}\text { oléate } \\
\text { de cholestérol }\end{array}$ & $\begin{array}{l}\mathrm{L} \\
\mathrm{I}\end{array}$ & $\begin{array}{r}30 \\
1750\end{array}$ & $\begin{array}{r}1748 \\
54\end{array}$ & $\begin{array}{r}1718 \\
5 t\end{array}$ & $\begin{array}{l}1780 \\
1772\end{array}$ & 4,847 & 96,95 \\
\hline $\begin{array}{c}\text { linoléate } \\
\text { de cholestérol }\end{array}$ & $\begin{array}{l}\mathrm{L} \\
\mathrm{E}\end{array}$ & $\begin{array}{r}39 \\
1692\end{array}$ & $\begin{array}{r}1844 \\
170\end{array}$ & $\begin{array}{r}1805 \\
170\end{array}$ & $\begin{array}{l}1731 \\
1975\end{array}$ & 4,569 & 91,39 \\
\hline
\end{tabular}

légère activité hydrolytique. L,a suppression de la sécrétion pancréatique entraîne une disparition pratiquement totale de toutes les activités ( $y$ compris celle des contenus gastriques) à l'exception du contenu duodénal où l'hydrolyse n'est que très légèrement atténuée ( 80 contre $96 \mathrm{p}$. Ioo).

L'addition de $50 \mu 1$ de suc pancréatique à ces contenus permet la restauration des activités hydrolytiques.

\section{DISCUSSION}

\section{Action de la suppression de la sécrétion pancréatique en présence de surcharges en cholestérol}

La privation de sécrétion pancréatique limite considérablement 1'absorption du cholestérol sans toutefois l'annuler, comme le montre le rapport des vitesses d'accroissement des cholestérolémies entre animaux non opérés et opérés (dans un rapport de 6,5 à I). L'action sur 1'absorption intestinale est selon toute vraisemblance primordiale. De ce fait, l'absorption jéjunoiléale du cholestérol et de ses esters est fortement réduite par la privation de sécrétion pancréatique. Au contraire, au niveau du duodénum, cet effet reste peu sensible. 
Les augmentations du taux des esters de cholestéryle, rendant compte d'une grande part des élévations de lipémie et cholestérolémie, confirment les données de WANG (r954) et PoPJAK (I949), ce dernier donnant des rapports $C_{L} / C_{E}$ de $0,23 \mathrm{chez}$ des animaux normaux. Seuls WEILLS et RONGONE (I969) ont trouvé des hypercholestérolémies localisées à la fraction libre (rapport $\mathrm{C}_{\mathrm{L}} / \mathrm{C}_{\mathrm{E}}=3$,I6). Selon RosE (1972), les régimes enrichis en cholestérol diminuent l'activité cholestérol estérifiante du plasma; le foie serait alors la principale source d'esters de cholestéryle. L'examen de la composition des lipides plasmatiques des différents lots d'animaux montre que les variations sont presque exclusivement localisées aux triglycérides (TG) et esters de cholestéryle (EC). Les pourcentages de ces deux fractions peuvent être exprimés en fonction des logarithmes des cholestérolémies totales en mg pour roo $\mathrm{ml}$, selon une relation linéaire :

$$
\begin{aligned}
& \text { p. Ioo } \mathrm{TG}^{2}=-28,2 \log [\text { cholestérol total }]+57,2 \\
& \text { p. Ioo } \mathrm{EC}= \\
& 4 \mathrm{I}, \mathrm{O} \log [\text { cholestérol total }]-8,0
\end{aligned}
$$

POPJAK (I949) de son côté, a obtenu des relations de ce type entre cholestérolémie libre et acides gras des lipides neutres, alors que MARQUiE, AGID et BonNET (I97I) ont dégagé des corrélations entre acides gras libres, cholestérol libre et $\beta$-lipoprotéines mais n'ont pas obtenu de corrélation significative avec les esters de cholestéryle et triglycérides, en utilisant cependant des surcharges journalières inférieures aux nôtres $(400 \mathrm{mg} / \mathrm{j})$.

Les relations obtenues montrent que, lorsque les cholestérolémies s'écartent sensiblement de la normale, de profondes perturbations du profil lipidique apparaissent rapidement.

Du fait des mécanismes de régulation de la synthèse du cholestérol (SIPERSTEIN et FAGAN, I957), seule l'utilisation de régimes enrichis en cholestérol permet de dégager le rôle de la sécrétion pancréatique, alors que l'étude des cholestérolémies en régime normal ne montre pas de changements notables. Chez l'Homme, dans des conditions très particulières (déficience congénitale de la fonction pancréatique) BELL et WEL,L (I968) ont observé ainsi des baisses de la cholestérolémie, mais chez le Chien dépancréaté aucun effet n'a pu être démontré (LiN et al., I957).

\section{Rôle de la sécrétion pancréatique dans les processus de l'hydrolyse des esters de stérols et de captation par la muqueuse intestinale in vivo}

La vitesse de disparition des doses traceuses in vivo montre que le cholestérol libre est mieux absorbé que sous sa forme estérifiée. Le terme d'absorption, d'après la description de ce processus par DAy, WAHLQVist et CAMPBELL (I970) désigne ici non pas un transfert vers le sang et la lymphe, toujours lent dans le cas du cholestérol, mais une incorporation par la muqueuse intestinale. Nos expériences ne nous permettent pas d'avancer d'hypothèse sur le mécanisme de captation du cholestérol libre. Nous savons seulement que l'absence d'hydrolyse des esters par privation de suc pancréatique diminue considérablement la fixation du cholestérol par la muqueuse intestinale.

In vivo, l'estérification peut être considérée comme négligeable alors que l'hydrolyse des esters est presque toujours intense. Comme le cholestérol libre, bien absorbé, disparaît rapidement de la lumière intestinale il est plausible que la présence de 
cholestérol libre après addition d'oléate de cholestéryle soit l'indice d'une activité hydrolytique dans le contenu prélevé. En ce qui concerne le grêle distal et le côlon, cette hydrolyse semble s'amorcer dans le contenu duodénal, voire gastrique ; cette action subsistant d'ailleurs dans une large mesure en l'absence de sécrétion pancréatique. La présence de ces activités en amont du canal de Wirsung pose évidemment un problème nouveau dans la mesure où l'on attribuait jusqu'alors aux activités cholestérol estérasique une origine exclusivement pancréatique (HERNANDEZ, Chaikoff et Kiyasu, I955).

L'incorporation du cholestérol par la muqueuse intestinale chez le Lapin est principalement jéjunale et non iléale comme l'avaient proposé BuchWALD et GEBHARD (I964) par la technique traumatisante " d'intestinal bypass".

Si les différentes propriétés (hydrolyse intraluminale, captation, estérification dans la muqueuse) semblent à quelques degrés près de nature assez voisine tout au long du grêle chez le Lapin normal, la suppression de la sécrétion pancréatique permet de diviser physiologiquement le grêle en 2 parties :

- le jéjuno-iléon, étroitement dépendant de la présence du suc pancréatique,

- le duodénum dont la captation représente $I_{5}$ à 20 p. Ioo de la captation globale du grêle et qui semble peu dépendante de la présence de suc pancréatique.

Cette pénétration du cholestérol dans la muqueuse duodénale contredit les conceptions classiques sur deux points :

- les deux sécrétions, biliaire et pancréatique, ne sont pas indispensables pour une absorption normale contrairement aux conceptions de SchUTz et STRECKER (I97I). On peut envisager soit une perméabilité au cholestérol particulière au duodénum, soit une émulsification suffisamment fine à la sortie de l'estomac pour permettre cette captation duodénale ; il faudrait alors admettre que cette émulsion se désorganiserait rapidement ou serait impropre à l'absorption jéjunoiléale.

- le rapport isotopique $\left({ }^{3} \mathrm{H} /{ }^{11} \mathrm{C}\right)$ des esters, nettement supérieur à celui du cholestérol libre, suggère une captation directe d'esters de cholestéryle. Ces données sont en contradiction avec celles obtenues par TREADWELL et VAHOUNy (Ig64) et GoODMaN et Shiratori (I969), ce phénomène n'a jusqu'alors été observé qu'in vitro par Smith, Hauk et Treadweli (I958).

Dans la muqueuse du jéjunum et de l'iléon le pourcentage d'esters est loin d'être négligeable chez les lapins opérés. Ce fait impliquerait que, contrairement aux conceptions d'Hernandez, Chaikoff et Kiyasu (I955) chez le Rat, subsiste une activité estérifiante dans la muqueuse, ce qui semble être en faveur de l'existence d'une cholestérol estérase propre à la muqueuse intestinale mais susceptible d'être activée en présence de suc pancréatique par un mécanisme qui reste à préciser.

\section{Activités cholestérol estérasiques du suc pancréatique et des contenus digestifs in vitro.}

Les épreuves in vitro font apparaître une très forte activité de la cholestérol estérase du suc pancréatique vis-à-vis des substrats insaturés. Si l'on compare nos résultats à ceux obtenus par SHAH, Lossow et CHAIKOFF (I965) chez le Rat nous obtenons, dans des conditions strictement identiques, $76,7 \mathrm{p}$. Ioo d'estérification avec l'acide oléique pour $0,8 \mathrm{mg}$ de protéines alors que ces auteurs n'observent qu'un taux 
de 67,7 p. Ioo avec I,6 à I,8 mg de protéines. C'est-à-dire que l'activité intrinsèque du suc pancréatique du Lapin s'avère deux fois plus grande que celle du Rat.

L'ordre des spécificités, en considérant l'estérification avec divers acides gras, est semblable à celui trouvé par les auteurs précédents et MuRTuY et GANGULY (I962), par contre, nous enregistrons des estérifications inférieures avec les substrats saturés: l'estérification par le stéarate est deux fois plus forte que pour le palmitate. Il semble donc que les critères de solubilité ne sont pas les seuls à intervenir (faible différence entre palmitate et stéarate) ; il existerait une spécificité vis-à-vis de la longueur de 1a chaîne carbonée. L'estérification procède d'un mécanisme différent de celui du plasma ( $\beta$-lécithine-cholestérol-acyltransférase) comme le montre la très faible synthèse d'ester lorsque le substrat est la dipalmitoyl-lécithine.

L'hydrolyse in vitro des esters de cholestéryle fait apparaître des résultats très différents selon les milieux utilisés. SWELL et TREADWELI. (I955), avec une dispersion utilisant de l'albumine et des sels biliaires, n'ont enrgistré d'hydrolyse qu'avec des esters d'acides courts (acétate, butyrate et caproate de cholestéryle); 1'hydrolyse de l'oléate représentant $6 \mathrm{p}$. Ioo de celle du butyrate ; VAHOUNy, WEERsING et TrEADWELL ( $1964 b)$ par contre, avec une émulsion utilisant des phospholipides et des sels biliaires, n'ont pas noté de différence d'action de l'enzyme selon la nature de l'acide.

Les épreuves réalisées à partir des contenus digestifs, peu pratiquées à l'exception des travaux de RosenFELD et HELLMAN (I97I), présentent l'intérêt de respecter dans une large mesure les paramètres ( $\mathrm{pH}$, concentration des agents tensioactifs, etc.) qui conditionnent le sens et l'intensité de l'action de la cholestérol estérase. Lues données ainsi obtenues recoupent celles acquises in vitro: l'estérification du cholestérol libre est négligeable alors que l'hydrolyse des esters utilisés est très forte.

Il apparaît une profonde différence entre les contenus duodénaux où se manifeste une très forte activité hydrolytique et le reste du tube digestif dont les activités, décroissantes en direction aborale, dépendent étroitement de la présence de la sécrétion pancréatique. L'addition de quantités égales d'enzyme pancréatique dans les homogénats de contenus digestifs des lapins opérés ne se traduit pas par des hydrolyses égales, mais hiérarchisées comme chez les sujet; normaux. La baisse d'activité en direction aborale peut être due, non pas à une diminution de la quantité d'enzyme présente, mais à une modification biochimique du milieu. Ceci implique qu'une activité cholestérol-estérasique latente peut être excrétée dans les cæcotrophes que le lapin réingère (THACKER et BRANDT, I955).

Les activités estérasiques enregistrées in vitro et in vivo dans les contenus gastriques n'ont jamais, à notre connaissance, été décrites. Le fait que des activités hydrolytiques subsistent jusque dans le cæcum et le côlon et la pratique de la cæcotrophie permettent d'envisager pour ces activités une origine pancréatique indirecte, d'autant plus que nous avons vérifié que l'enzyme pancréatique conserve une activité notable dans les conditions qui règnent dans l'estomac.

L'importante activité estérifiante présentée par le suc pancréatique in vitro ne se retrouve à aucun niveau. On pourrait pourtant s'attendre à observer une estérification des stérols libres dans la partie supérieure du grêle, avant que le $\mathrm{pH}$ n'ait été sensiblement relevé. Plusieurs facteurs peuvent se conjuguer pour limiter l'expression de l'activité estérifiante de l'enzyme pancréatique :

- les méthylnaphtoquinones peuvent inhiber l'action estérifiante de la cholestérol estérase pancréatique tout en respectant l'action hydrolytique (MoNTINI et 
ARrigo, I952), or le régime herbivore du Lapin maintient un taux élevé en vitamines $\mathrm{K}$ dans son tractus digestif.

- les acides biliaires en fortes concentrations peuvent, même si les conditions de $\mathrm{pH}$ sont favorables à l'estérification, renverser le sens de la réaction et amorcer une hydrolyse des esters (KELLY et NEWMANN, I97r). I1 faut noter toutefois que ce phénomène a été mis en évidence avec le taurocholate alors que chez le Lapin le principal acide biliaire est le glycodésoxycholate (GREGG et POLLEY, I966). Cette dernière particularité soulève un problème supplémentaire car VAHOUNY, WEERSING et 'TREADWELL ( 1965 ) ont montré que le glycodésoxycholate n'active pratiquement pas l'hydrolyse de l'oléate de cholestéryle, à la différence du cholate et de ses dérivés conjugués.

\section{CONCLUSIONS}

La privation de sécrétion pancréatique par ligature du canal de Wirsung ne s'accompagne pas de variations importantes de cholestérolémie chez le Lapin en régime normal. Par contre chez ces lapins opérés soumis au régime enrichi en cholestérol, l'assimilation du cholestérol d'origine exogène est réduite à un sixième environ.

Chez le Lapin normal l'incorporation du cholestérol libre alimentaire par la muqueuse intestinale se fait surtout dans le jéjunum, tandis que le cholestérol libéré à partir de ses esters dans la lumière intestinale sera absorbé préférentiellement dans la région proximale de l'iléon. Cette absorption dépend étroitement de la présence du suc pancréatique.

L'absorption duodénale du cholestérol ne représente environ que is p. Ioo du cholestérol total absorbé par le grêle. Cette absorption semble s'appliquer également aux esters de cholestéryle.

Les activités cholestérol estérasique des contenus digestifs du Lapin se limitent à l'hydrolyse des esters de stérols. La cholestérol estérase du suc pancréatique joue le rôle principal. Cependant le contenu duodénal présente une forte activité hydrolytique qui lui est propre.

L'activité hydrolytique du contenu gastrique ne peut trouver d'explication rationnelle que dans la pratique de la coecotrophie chez le Lapin.

Reçu pour publication en janvier 1974 .

\section{SUMMARY}

ROLF, OF PANCREATIC EXOCRINE, SFCRETION IN INTESTINAI, ABSORPTION OF CHOLESTEROL IN THE RABBIT

A lack of pancreatic secretion resulting from ligature of the Wirsung canal is not accompanied by any variation of cholesterolemy in rabbits on a normal diet. In contrast in operated rabbits receiving a cholesterol enriched diet ( $\mathrm{I}$ g/day), assimilation of cholesterol of exogenous origin (measured by the accumulation of total plasma cholesterol with time) is reduced to approximately one sixth of that in non operated rabbits. The particularity of hypercholesterolemies (due mainly to cholesteryl esters), and the absence of serious perturbations of the different plasma lipid parameters after ligature of the Wirsung canal, are discussed. 
The administration of emulsions containing cholesterol- $4^{-14} \mathrm{C}$ and cholesteryl oleate $\left({ }^{3} \mathbf{H}_{\mathbf{G}}\right)$ made it possible to show that uptake of cholesterol by the intestinal mucosa occurs mainly in the jejunum in normal rabbits. The cholesterol liberated from esters in the intestinal lumen is preferentially incorporated in the region of the ileum.

Jejunoileal absorption is closely corretelated with the presence of pancreatic secretion. Absorption by the duodenal mucosa, representing about i 5 p. roo of the total cholesterol absorbed in the small intestine, continues in the absence of pancreatic secretion. The duodenal mucosa appears to absorb cholesteryl esters also.

Rabbit pancreatic juice contains a cholesterol esterase with a high hydrolytic activity viz. esters of short-chain or unsatured fatty acids at $\mathrm{pH} 7.2$ and esterifying activity viz. unsatured fatty acids at $\mathrm{pH} 6.2$.

After administration of cholesteryl oleate in vivo or incubation with digestive homogenates in vitro, it was found that esterase activities of the digestive tube are orientated in the direction of cholesteryl ester hydrolysis.

The hydrolytic activities of the contents of the jejunum, ileum and, to a lesser extent, the caecum and colon originate from the cholesterol esterase of the pancreatic juice. Although a very high level of hydrolysis in the duodenal contents remains in the absence of pancreatic secretion, hydrolytic activity of the gastric contents depends equally on pancreatic secretion. The origin of the gastric enzyme and orientations of cholesterol esterase activities in the digestive tube are discussed.

\section{RÉFÉRENCES BIBLIOGRAPHIQUES}

Beher W. T., Baker G. D., Penney D. G., 1963. Time course of fecal steroid- ${ }^{14} \mathrm{C}$ in various rodents. Amer. J. Physiol., 205, I I59-I I62.

BELL C. C., WELL L. L., I968. Effect of total pancreatectomy on cholesterol absorption and cholesterol serum level in man. Proc. Soc. Exptl. Biol. Med., 128, 575-577.

Beukers H., Veltkamp W. A., Hoogwinkel J. M., I969. A method for the determination of the molecular distribution on free and esterified cholesterol in serum by thin-layer chromatography. Clin. Chim. Acta, 25, 405-408.

Borgstrom B., Lindhe B. A., Wlodawer P., I958. Absorption and distribution of cholesterol $4^{-14} \mathrm{C}$ in the rat. Proc. Soc. Exptl. Biol. Med., 99, 365-368.

Borgstrom B., 1960. Studies on cholesterol absorption in the human. J. Clin. Invest., 99, 809-815.

Borgstrom B., 1968. Quantitative aspect of the intestinal absorption of cholesterol and sitosterol in the rat. J. Lip. Res., $\mathbf{9}, 473-48$ I.

Borja C. R., Vahouny G. V., Treadwell C. R., I964. Role of bile and pancreatic juice in cholesterol absorption and esterification. Amer. J. Physiol., 206, 223-228.

Buchwald D. D., Gebhard R. L., I964. Effect of intestinal bypass on cholesterol absorption and blood levels in the rabbit. Amer. J. Physiol, 20\%, 567-572.

Byers S. O., Friedmann M., Gunning B., i953. Observations concerning the production and excretion of cholesterol in the mammals. IX. The intestinal site of absorption and excretion of cholesterol. Amer. J. Physiol, 175, 375-379.

Chevalier F., Phillipot J., r963. Sort du cholestérol des chylomicrons après leur introduction dans du sérum. Ann. Nutr. Alim. Fr., 17, 4 at 5, 225-235.

Cook R. P., Kliman A., Fieser L., 1954. The absorption and metabolism of cholesterol and its main companions in the rabbit with observations on the atherogenic nature of the sterols. Arch. Biochim. Biophys., 52, 439-450.

Dallochio M., Crockett R., Razaka G., Sallenave M., Nicouleau P., Bricaud H., BrousTET P., rg69. Athérosclérose expérimentale par régime hypercholestérolé : évolution à long terme (étude chez le lapin). Arch. Mal. Cour, suppl. no $2,54-69$.

Day A. J., Wahlovist M. L., Campbell D. J., I970. Differential uptake of cholesterol and different cholesterol esters by atherosclerosis intima in vivo and in vitro. Atherosclerosis, 11, $30 \mathrm{I}-320$.

Delsal J. L., I944. Nouveau procédé d'extraction des lipides dí sérum par le méthylal. Application aux microdosages du cholestérol, des phosphoaminolipides et des protéines. Bull. Soc. Biol., 26, 99 -I05.

Dunham L. W., Fortner R. E., Moore R. D., Culp H. W., Nice C. N., i959. Comparative lymphatic absurption of $\beta$-sitosterol and cholesterol by the rat. Arch. Biochim. Biophys., 82, 50-61.

Favarger P., I942. Le rôle du cholestérol dans la résorption des graisses. Arch. Int. Pharmacodyn. 68, $409-4 \mathrm{I} 6$.

Favarger P., Metzger E. F., I952. La répartition intestinale du deutéricholestérol et sa répartition dans l'animal sous forme libre et estérifiée. Helv. Chim. Acta., 35, i8II-I8I9.

Feldman E., Henderson D. H., I969. Cholesterol absorption by jejunum and ileum. Biochim. Biophys. Acta., 193, 22 1-224. 
Gallo-Torres H. G., Miller O.N., Hamilton S. G., i97I. Further studies on the role of bile salts in cholesterol esterification. Arch. Biochim. Biophys., 143, 22-36.

Goodman et Shrratori, r969. Cités par Vahouny et Treadwell dans "Cholesterol absorption "p. I4 3 in Handbook of Physiology, Saunders Éd.

Gregg J. A., Polley J. R., I966. Excretion of bile acids in normal rabbits. Amer. J. Physiol,, 211, II 47 -II 5 I.

Hellman L., Frazell E. L., Rosenfeld R. S., ig6o. Direct measurement of cholesterol absorption via the thoracic duct in man. J. Clin. Invest., 39, I288-1294.

Hernandez H. H., Chaikoff I. L., Dauben W. G., Abraham S. A., I954. The absorption of ${ }^{14} \mathrm{C}$-labeled epicholesterol in the rat.' J. Biol. Chem., 206, 757-765.

Hernandez H. H., Chalkoff I. L., Kryasu J.Y., I955. Role of pancreatic juice in cholesterol absorption. Amer. J. Physiol., 181, 523-526.

Houx N.W., 1969. Liquid scintillation radioassay by thin-layer chromatograms. Annal. Biochem., 30, 302-305.

Kelly A. J., Newman A. I., I97I. Pancreatic sterol ester hydrolase reversal of the reaction by bile salt. Biochim. Biophys. Acta, 231, 558-559.

Korzenovsky M., Walters C., Harvey O., Diller E., rg6o. Some factors which influence catalytic activity of pancreatic cholesterol esterase. Proc. Soc. Exptl. Biol. Méd., 105, 303-305.

Kuksis A., I966. Quantitative lipid analysis by combinated thin-layer and gas-liquid chromatographic systems. Chromatog. Rev., 8, I73-207.

Lin T. M., Karvinen E., Ivy A. C., I957. Role of pancreatic digestion in cholesterol absorption. Amer. J. Physiol, 190, 2 I4-220.

Lutton C., Chevalier F., 1972. Analyse des stérols des contenus digestifs et des fèces du rat. Biochim. Biophys. Acta, 260, I33-I 45 .

Marquie G., Agid R., Bonnet L., ig7r. Mise en évidence du rôle athérogène des acides gras libres plasmatiques lors des mobilisations lipidiques induites par le cholestérol chez le lapin. C. R. Soc. Biol. 165, 713-717.

Montini T., ARrigo L., I952. Sulla presenza di un fattore lipotropo nel succo pancreatico en negli esterati di pancreas. Bull. Soc. Ital. Biol. Sper., 28, 209-212.

Morrison W. R., Smith L. L., I964. Preparation of fatty acids methyl esters and dimethylacetals from lipids with boron fluorid-methanol. J. Lip. Res., 5, 600-608.

Murdock H. R., I969. Anesthesia in the rabbit. Fed. Proc., 28, I5Io-I5I5.

Murthy S. K., Ganguly J., I962. Studies on cholesterol esterases of small intestine and pancreas of rat. Biochem. J., 83, 460-469.

Novitski A. A., I97I. Mechanism likely to cause resistance to alimentary hypercholesterolemia in rabbits, Cor, et Vasa, 13, $280-290$.

PopJak G., r 949 . The effect of feeding cholesterol without fat on the plasma lipids of the rabbit : the role of cholesterol in fat metabolism. Biochem. J., 40, 608-62I.

Ribet A., Pascal J. P., r968. Le pancréas exocrine. Masson et Cie, éd. ; p. 18 et 31 .

Rose H. G., r972. Origin of cholesteryl esters in the blood of cholesterol fed rabbits : relative contributions of serum lecithin-cholesterol acyltransferase and hepatic ester synthesis. Biochim. Biophys. Acta, 260, 312-326.

Rosenfeld R. J., Hellman L., r97i. Reduction and esterification of cholesterol and sitosterol by homogenates of feces. J. Lip. Res., 12, 192-197.

ShaH S. M., Lossow W. T., ChaikofF I. L., 1965. In vitro esterification of cholesterol by pancreatic juice and aceton powder extracts of small intestine : the effect of unsatured fatty acids upon esterification with satured fatty acids. J. Lip. Res., 6, 228-232.

Shultz S. G., Strecker C. K., I97I. Cholesterol and bile salt influxes accross brush border of rabbit jejunum. Amer. J. Physiol, 220, 59-65.

Siperstern M. D., FaGAN V. M., 1957. Role of glycolysis in fatty acids and cholesterol synthesis in normal and diabetic rats. Science, 126, ror 2-Ior3.

Smith A. L., Hauk R., Treadwell C. R., I958. Uptake of cholesterol and cholesterol esters by inverted sacs of rat intestine. Amer. J. Physiol., 198, 34-40.

Swell L., Treadwell C. R., 1955. Cholesterol esterases. VI. Relative specificity and activity of pancreatic cholesterol esterase. J. Biol. Chem., 212, I4I-I5o.

Swell L., Trout E. C., Hopper J. R., Field H., Treadwell C. R., I958. Mechanism of cholesterol pools of mucosa after feeding cholesterol-4 ${ }^{14} \mathrm{C}$. J. Biol. Chem., 233, 49-53.

Swell L., Treadwell C. R., r962. Enzymic preparation of labeled unsatured fatty acid esters of cholesterol. Anal. Biochem., 4, 335-339.

Thacker E. J., Brandt C. S., 1955. Coprophagy in the rabbit. J. Nutr., 55, 375-379.

Tranchant J., rg68. Manuel pratique de chromatographie en phase gazeuse. Masson Éd.

Treadwell C. R., Vahouny G. V., 1958. Absorption of cholesterol esters in the lymph-fistula rat. Amer. J. Physiol., 195, 56r-520. 
Treadwell C. R., Vahouny G. V., I964. Absolute requirement for free sterol for absorption by rat intestinal mucosa. Proc. Soc. Exptl. Biol. Med., 116, 496-498.

VAhouny G. V., WeErsing S., Treadwell C. R., I 964 a. Taurocholate protection of cholesterol esterase against proteolytic inactivation. Biochem. Biophys. Res. Comm., 15, 224-229.

Vahouny G. V., Weersing S., Treadwell C. R., I964 $b$. Micelles solubilized substrates and cholesterol esterase activity in vitro. Arch. Biochem. Biophys, 107, 7-I5.

Vahouny G. V., Weersing S., Treadwell C. R., 1965. Function of specific bile acids in cholesterol esterase activity. Biochim. Biophys. Acta, 93, 607-6r6.

WANG I. C., 1954. Plasma lipid partition of normal and cholesterol fed rabbit. J. Mt. Sinä̈ Hosp., 21, 19-29.

Wells I. C., Rongone E. L., I969. Dietary cholesterol and serum cholesterol esterifying activity in rabbits. Proc. Soc. Exptl. Biol. Med., 130, 66r-664.

ZLATkis A., ZAK B., Boyle A. J., 1953. A new method for direct determination of serum cholesterol. J. Lab. Clin. Med., 41, 486-492. 